\begin{tabular}{ccc}
\hline International Journal of Engineering \& Technology, $7(4.13)(2018) 74-80$ \\
SPC \\
Website: www.sciencepubco.com/index.php/IJET \\
Research paper
\end{tabular}

\title{
Comparison of horizontal axis wind turbine (HAWT) and vertical axis wind turbine (VAWT)
}

\author{
Muhd Khudri Johari*, Muhammad Azim A Jalil, Mohammad Faizal Mohd Shariff \\ Universiti Kuala Lumpur - Malaysian Institute of Aviation Technology, Dengkil, Selangor, Malaysia \\ *Corresponding author E-mail: mdkhudri@unikl.edu.my
}

\begin{abstract}
As the demand for green technology is rising rapidly worldwide, it is important that Malaysian researchers take advantage of Malaysia's windy climates and areas to initiate more power generation projects using wind. The main objectives of this study are to build a functional wind turbine and to compare the performance of two types of design for wind turbine under different speeds and behaviours of the wind. A three-blade horizontal axis wind turbine (HAWT) and a Darrieus-type vertical axis wind turbine (VAWT) have been designed with CATIA software and constructed using a 3D-printing method. Both wind turbines have undergone series of tests before the voltage and current output from the wind turbines are collected. The result of the test is used to compare the performance of both wind turbines that will imply which design has the best efficiency and performance for Malaysia's tropical climate. While HAWT can generate higher voltage (up to $8.99 \mathrm{~V}$ at one point), it decreases back to $0 \mathrm{~V}$ when the wind angle changes. VAWT, however, can generate lower voltage $(1.4 \mathrm{~V})$ but changes in the wind angle does not affect its voltage output at all. The analysis has proven that VAWT is significantly more efficient to be built and utilized for Malaysia's tropical and windy climates. This is also an initiative project to gauge the possibility of building wind turbines, which could be built on the extensive and windy areas surrounding Malaysian airports.
\end{abstract}

Keywords: HAWT; VAWT; wind energy; wind turbine.

\section{Wind energy}

Malaysia, just like most countries in the world, is producing most of its electricity by using coal and fossil fuel. Only around $10.74 \%$ of the country's electricity is generated from renewable source of energy that is hydropower due to geological situation of Malaysia [1]. According to a research, Malaysia has an average between 1.3 $\mathrm{m} / \mathrm{s}$ and $2.7 \mathrm{~m} / \mathrm{s}$ of wind speed inland, and variation from $3.5 \mathrm{~m} / \mathrm{s}$ to $4.5 \mathrm{~m} / \mathrm{s}$ of wind speed on coast line that is considered being low potential wind [2]. In the early 1990s, another wind energy potential study has been conducted at various cities in Malaysia. From a set of wind speed data collected by the Malaysian Meteorological Service Station for the research, it has been shown that Mersing and Kuala Terengganu have had the most potential for wind power with annual mean power of 85.61 and $32.50 \mathrm{~W} / \mathrm{m}^{2}$, respectively. A wind power potential that is less than $100 \mathrm{~W} / \mathrm{m}^{2}$ is considered low potential and is not suitable for wind power generation. The percentage for green energy is very low and Malaysia has to do something to reduce our dependency on coal and fossil fuel as our main source for power generation. For this reason, wind energy is again becoming an alternative as the modernization and development of technology take place. IMPSA, a private company specializing in power generation from renewable sources, has estimated that Malaysia has a capacity to produce power from the wind energy between 500 to $2000 \mathrm{MW}$ [3]. With $4675 \mathrm{~km}$ long coastline, Malaysia is ranked at $29^{\text {th }}$ among other countries in the world and this seems like a very good potential to develop the wind power capacity in Malaysia.

Though it is already known that wind power generation is unpopular in Malaysia due to its location in equatorial zone that results in irregular and relatively low wind speed, it does not impede various research and development for the wind turbine power generation in Malaysia with the help of development of wind turbine designs that are specific for low potential wind area. Up until now, Malaysia has only few significant progresses in commercial wind energy production. Small experimental projects such as those at Swallow Reef and Perhentian Island are proofs that installing wind power capacity is not an easy task due to low wind speeds and seasonal variability. A study has suggested that Malaysian researchers shift from the mesoscales winds to focusing on the macroscale wind as it is proven to be more effective [4]. This research intends to be a pioneer and future reference for that as the experiments involved will imitate the potential surroundings of large, flat lands such as vast areas surrounding airports rather than risking more failures to install wind turbines in the sea or near beach areas.

\section{HAWT and VAWT}

\subsection{Applications}

Just like windmills, wind turbines take the advantage of the wind energy and transform it into different form of energy. In this case study, wind turbine converts the kinetic energy of the wind into electrical energy. Wind turbines are used for various applications, from harnessing energy for an entire city to a small power generation for personal use.

Small wind turbines are usually selected for local usage. With the capability to produce electricity less than $100 \mathrm{~kW}$, they are usually installed in the isolated, remote and off-grid areas where there is no connection to the national grid [5]. Nowadays, the wind turbine technology has been used for everyday use and not only to power 
up a rural village, through various innovation and development. In December 2015, built by French Company, New Wind, the "wind tree" has been introduced to the world. It is a vertical wind turbine with several vertical blades, made in the shape of a tree. With just under $30 \mathrm{ft}$ tall and $23 \mathrm{ft}$ wide, the "wind tree" has 54 leaf-turbine that soundlessly rotating, harnessing energy up to $5.4 \mathrm{~kW}$ energy at a time from wind with speed less than $5 \mathrm{mph}$ [6]. Annually, the wind tree is capable of producing $2400 \mathrm{kWh}$ of electricity, enough to power up a house. In addition, they are pleasing to the eyes too.

\subsection{HAWT}

The HAWT concept as depicted in Figure 1 has already been used as early as 5000 B.C. where people extracting the energy from the wind to move boats along the Nile River [7]. Since then, the wind turbines have gone through significant innovation and improvisation in their design for optimum performance. HAWT consists of blades that extract wind energy on horizontal axis and are parallel to the ground. By facing the wind flow perpendicularly, the blades work and turn due to aerodynamic lift. HAWT is the most popular choice of wind turbine and has received more funding for research and development since it offers significant advantage over VAWT [8]. HAWT have a greater efficiency then VAWT when extracting energy from the wind force due to its design that allows it to extract the energy through the full rotation of the blades when placed under consistent wind flow [9]. It is also immune to backtracking effect [10].

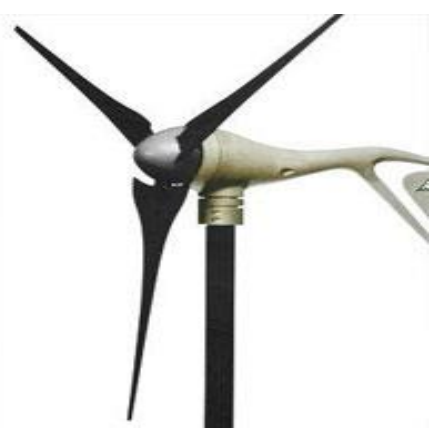

Fig. 1: Horizontal axis wind turbine (Source: Windpower Engineering \& Development)

However, HAWT has a major disadvantage, which is the fact that it must always be pointed in the wind direction to work efficiently. With unpredictable wind direction, extra mechanism is required to make sure the blades will always be facing the wind direction to extract maximum power output. Small wind turbine usually uses a simple wind vane to position itself into the direction of the wind stream. For larger wind turbine, it consists of a yaw meter to determine the correct position of the wind flow and a yaw motor to position the turbine into accurate direction of the wind [11]. Because of this disadvantage, HAWT works excellently in environment with consistent and low turbulence wind as it does not need to change its orientation too frequent.

\subsection{VAWT}

In contrast to HAWT, Figure 2 shows the blades for VAWT rotate perpendicularly to the ground and around the vertical axis. This type of turbine utilizes drag or lift or a combination of the two to operate. VAWT has also been used for ages and in fact, the first windmills that people have ever known are VAWT before HAWT appears and becomes popular at some points in the history of wind turbine. There are generally two main designs of VAWT and both designs work on different principles. The first design is Savonius that uses drag forces to work just like a water wheel and the other design is Darrieus that uses aerodynamic blade to generate lift and turn the turbine.

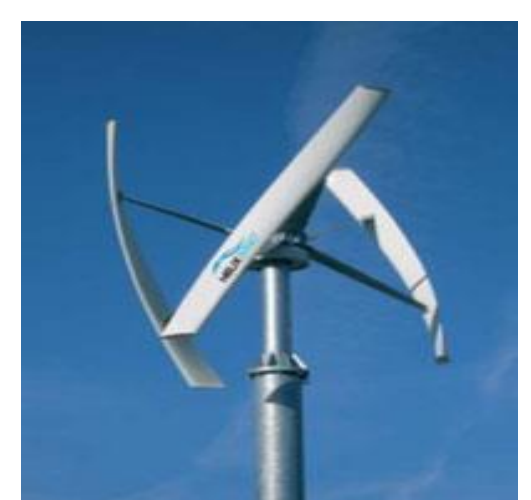

Fig. 2: Vertical axis wind turbine

(Source: Windpower Engineering \& Development)

Although VAWT has not been given as much attention as HAWT in its research and development, it has several significant advantages compared to HAWT. Unlike HAWT that is required to face the wind stream all the time in order to give the optimum output, VAWT is omnidirectional and can receive wind from any direction [12]. VAWT is the best choice to be installed in the slow and more turbulent wind environment such as urban areas because it can generally start to produce power at such low wind speed. The system for VAWT such as gearbox and other equipment can be packed together and installed closer to the ground, hence eliminating the need for extra cost for maintenance and making it easier to be controlled [13]. Finally, the VAWT are quieter than HAWT too. However, the disadvantage of VAWT also cannot be ignored easily. VAWT is inefficient in high speed wind environment because it has very low starting torques and issues on its dynamic stability. VAWT is also vulnerable to backtracking because its blade moves in the same direction to the wind and thus the blades need to travel back into the wind flow before being pushed back around [14]

It is important to note that previous studies comparing VAWT and HAWT have shown mixed results. There can either be that there is no significant difference between them [15] or one is simply better than the other [16].

\subsection{D Printing}

Thermoplastic is typically used for prototype development as it is easy to handle. Thermoplastic becomes malleable when heated at certain temperature, hence allowing it to be moulded and sculpted into the intended shape prior to cooling. There are several types of thermoplastic that can be used for 3D printing such as Polylactic Acid (PLA), Acrylonitrile Butadiene Styrene (ABS), Polyamide (PA), Thermoplastic Elastomer (TPE) and High Impact Polystyrene (HIPS). However, PLA and ABS are the most accessible ones around and they have their own properties that need to be looked at before considering using any of these two materials.

PLA thermoplastic is made up of the building blocks of lactic acid that are derived from sugars and can be found in the common crop such as corn, which belongs to the aliphatic polyesters family [17]. This makes PLA not only bio-based polymer but also compostable. Although PLA is very strong and have very high stiffness, it has a few weaknesses that limit it from being used for wider application. PLA is brittle and has poor thermal stability at relatively low temperature [18]. Compared to PLA, ABS polymer is synthesized from three monomeric chemicals: acronym, butadiene and styrene [19]. ABS thermoplastic is petroleum-based polymer and broadly used in several industries. ABS is known for its balance properties including strength, stiffness, toughness and thermal stability. Table 1 presents the detailed comparison of both PLA and ABS that has been derived from a previous study. 
Table 1: Properties of ABS and PLA

\begin{tabular}{|c|c|c|}
\hline Properties & ABS & PLA \\
\hline Tensile strength & $27 \mathrm{MPa}$ & $37 \mathrm{MPa}$ \\
\hline Elongation & $3.5-50 \%$ & $6 \%$ \\
\hline Density & $1.0-1.4 \mathrm{~g} / \mathrm{cm}^{3}$ & $1.3 \mathrm{~g} / \mathrm{cm}^{3}$ \\
\hline Melting point & N/A (amorphous) & $173^{\circ} \mathrm{C}$ \\
\hline Biodegradable & No & Yes \\
\hline Glass transition temperature & $105^{\circ} \mathrm{C}$ & $60^{\circ} \mathrm{C}$ \\
\hline
\end{tabular}

\section{Methodology}

Both types of wind turbine for this research have been constructed by using 3D printer. The material used is PLA thermoplastic. For VAWT, Darrieus design has been chosen and a simple HAWT has been used for this study. Both blades, as illustrated in Figure 3, are designed using CATIA software before the file is being translated into STL format to be read and printed by the 3D printer.

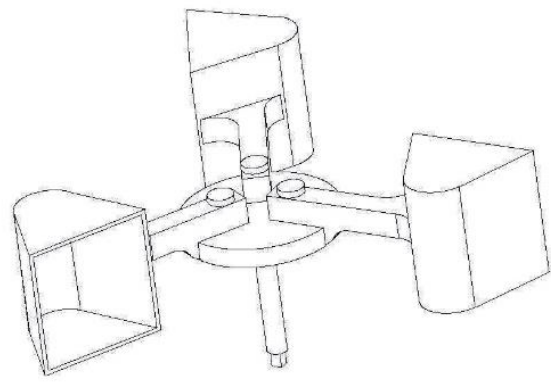

(a)

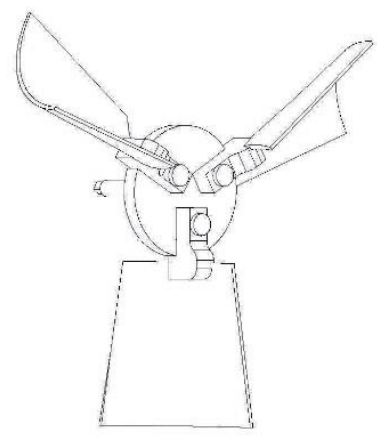

(b)

Fig. 3: Proposed designs of wind blade section, (a) VAWT, (b) HAWT

The power generator selected for this study is a permanent magnet generator. Before the generator is selected, two tests have been arranged for the generator to verify the relationship between variable RPM of the commutator and the output voltage and current generated. This is essential to ensure that the generator chosen will generate the voltage accordingly and obey the Faraday's Law. In these tests, the speed of magnetic flux cutting is manipulated and the generated voltage and current is the responding variable.

For the first test, the generator is not connected to any load. The generator shaft is driven by 60 RPM DC motor as the testing motor, with model number ZGB37RG58i, rated $12 \mathrm{~V}$ through same size of gearing. The input voltage to the DC motor is varied from $0 \mathrm{~V}$ to $9 \mathrm{~V}$ by using variable resistor to manipulate the RPM of the motor, hence vary the RPM of the generator. Two multimeters are used to determine the output voltage to the DC motor and the generated voltage from the generator. The arrangement and wiring diagram for the test can be seen in Figure 4. Output voltage reading is done three times and the average reading is taken.

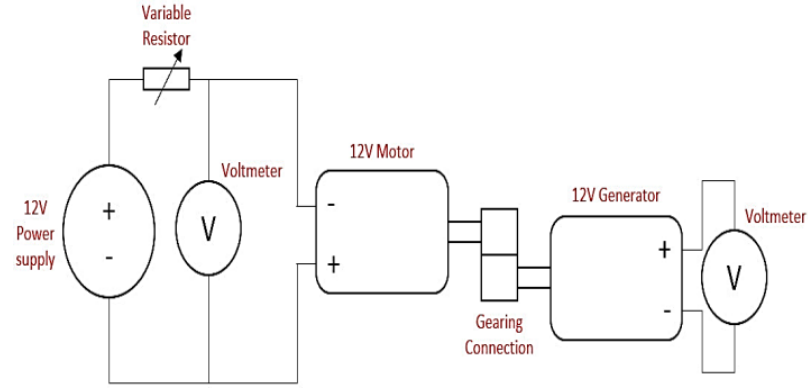

Fig. 4: Generator without load test wiring diagram

Just like in the first test, the arrangement for the second test is the same but with additional load. A bulb, rated $12 \mathrm{~V} 3 \mathrm{~W}$, is attached to the generator. An ammeter is connected in series with the bulb to measure its current. The arrangement and also wiring diagram for the test can be seen in Figure 5.

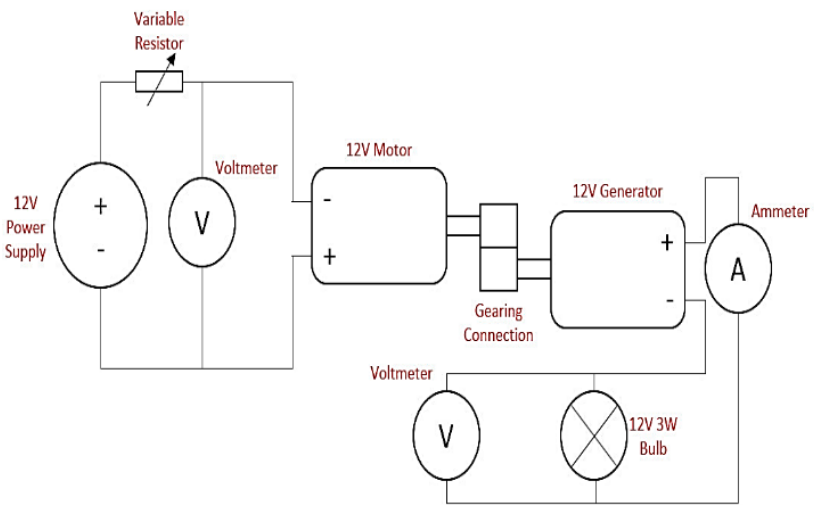

Fig. 5: Generator with load test wiring diagram

To measure the power generated by the generator, wires from the generator are passed through the voltmeter and ammeter. The current and voltage output are taken, and the power generated is calculated. The anemometer is used to measure wind stream speed. The arrangement and wiring diagram for the wind turbine can be seen in Figure 6.

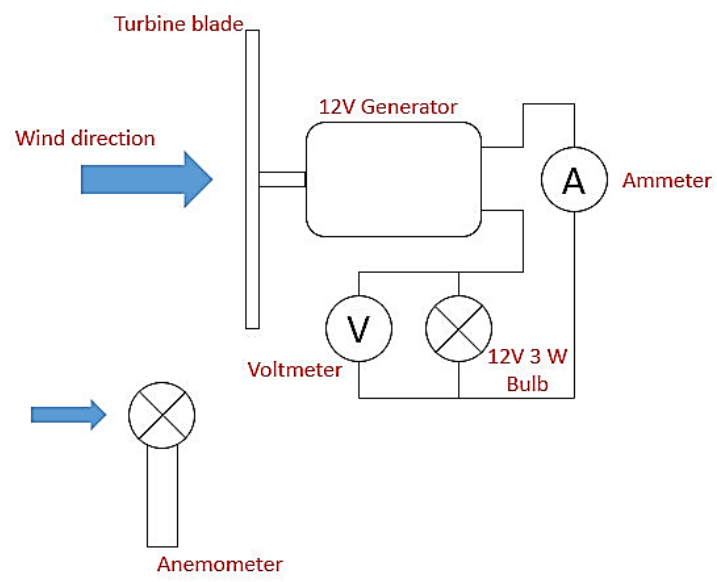

Fig. 6: Wind turbine wiring diagram

Both wind turbines are tested in two different environment: indoor testing with steady air stream source and outdoor testing for ambient air stream. For indoor testing, which is reported in this paper, there are two variables that are manipulated. First is the speed of air stream source and second is angle of the air source with respect to the direction of wind turbine. Both variables are varied in order to observe their effects on the performance of both types of wind turbine against certain behaviour of the wind. 
The first variable that is varied during the indoor testing is speed of the airstream. The speed of air coming from air stream source is varied and output voltage and current readings are taken. Just like the generator testing, the wind turbines are tested with load $(12 \mathrm{~V}$, $3 \mathrm{~W}$ bulb) and without load. For the second variable, which is the wind angle, the direction of air source with respect to the direction of the wind turbine and anemometer is varied while maintaining the speed of air stream source. The test arrangement can be seen in Figure 7.

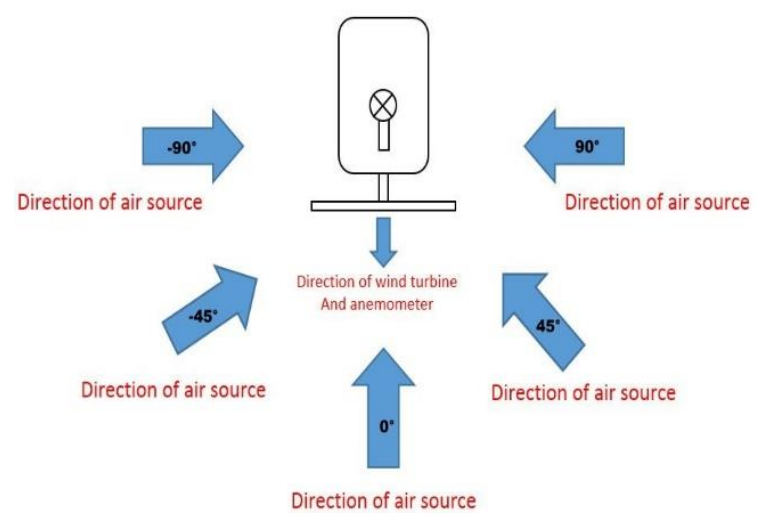

Fig. 7: Indoor testing plan

\section{Analysis}

\subsection{Functional wind turbines}

The functional wind turbine prototype has been constructed using two types of material, which are PLA thermoplastic for the blade section and steel for the stand. This prototype, as shown in Figure 8 and Figure 9, is equipped with block bearing, generator section and metal stand. Both wind turbines have undergone a functional test and successfully generating power.

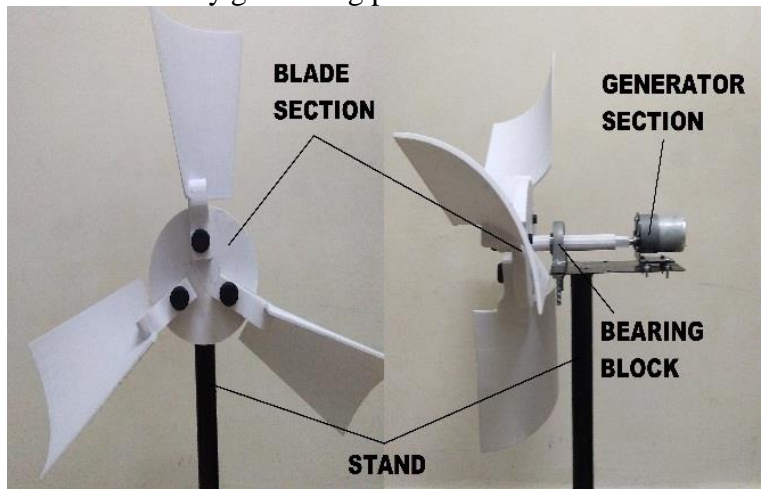

Fig. 8: VAWT prototype

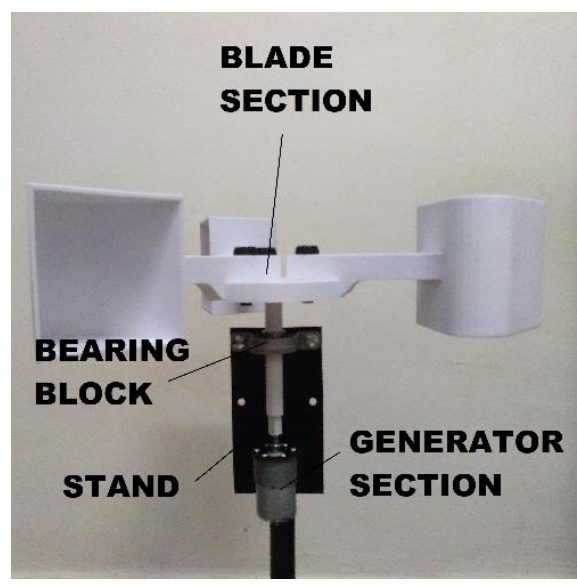

Fig. 9: HAWT prototype
The main section of the wind turbine is the blade where both designs are using PLA thermoplastic as the main material. Both prototypes have been constructed using $3 \mathrm{D}$ printing technique. Prototype of HAWT blade section consists of four main parts which are blades, center, pin and adaptor. Just like HAWT, the prototype of VAWT blade section also consists of 4 main parts, which are wind catcher, center, pin and adaptor. Table 2 and Table 3 below list the details of the parts.

Table 2: HAWT parts details

\begin{tabular}{|c|c|c|c|}
\hline Part Number & Part & Qty. & Weight (G) \\
\hline AJ1 & Centre Part & 1 & 77 \\
\hline AJ2 & Wind Blade & 3 & 60 \\
\hline AJ3 & Lock Pin & 3 & 6 \\
\hline AJ4 & Generator Adapter & 1 & 1 \\
\hline \multicolumn{3}{|c|}{ Total Weight } & 276 \\
\hline
\end{tabular}

Table 3: VAWT parts detail

\begin{tabular}{|c|c|c|c|}
\hline Part number & Part & Qty. & Weight (g) \\
\hline AJ1 & Centre part & 1 & 77 \\
\hline AJ5 & Wind catcher & 3 & 118 \\
\hline AJ3 & Lock pin & 3 & 6 \\
\hline AJ4 & Generator adapter & 1 & 1 \\
\hline \multicolumn{3}{|c|}{ Total Weight } & 450 \\
\hline
\end{tabular}

Both the weight and material of the prototype have been analyzed carefully. It can seen that the weight of VAWT is almost double of that for HAWT. This has significantly affected the performance of the prototype as more weight produces higher torque. Much faster wind speed is needed to turn VAWT than HAWT to produce the same amount of electrical power. The weight, as well as torque, is important to be considered in designing wind turbines. Torque is not only affected by weight of the blade section but also the generator and friction in bearing.

A major drawback in using PLA thermoplastic compared to ABS is its low glass transition temperature at $60^{\circ} \mathrm{C}$. Though PLA thermoplastic is easier and safer to use, and have a better level of print detail, it is prone to warping and melting when it is stored in hightemperature locations. These prototypes have melted and warped after being stored inside a car at $3.00 \mathrm{pm}$. From this finding, it can be concluded that PLA thermoplastic is not suitable to be used for prototype that is built for high temperature environment application. The high ambient temperature, especially in the hot countries such as Malaysia, can get as high as $40.0^{\circ} \mathrm{C}$ [20]. The temperature issue can be worsen with additional heat coming from friction and generator that affect the material of the prototype during its operation.

\subsection{Generator details}

The power generator selected for this study (refer specifications in Table 4) is a permanent magnet generator, JGB37-3530 $12 \mathrm{~V}$ DC geared motor that is turned into a generator. It is equipped with the gearbox and holder. The generator is connected to the blade section through the adapter. The selection of generator is important as it will affect the total torque of the wind turbine. An ideal choice is a generator with low torque and high-power output. This can reduce the minimum wind speed required to turn the generator and produce power. The diameter of the blade section is determined by the torque of the generator as longer diameter blade design is required to increase the moment to overcome it. Before the generator is selected, two tests have been arranged for the generator to verify the relationship between variable RPM of the commutator and the output voltage and current generated. Two generators have been tested, JGB37-3530 and M3N-2 generator motors, where in this test the speed of the magnetic flux cutting is manipulated. The generated voltage and current are the responding variables. The generators are tested with load $(12 \mathrm{~V}, 3 \mathrm{~W}$ bulb) and without load.

Table 4: Generator specifications

\begin{tabular}{|c|c|}
\hline Motor model & JGB37-3530 \\
\hline Gear ratio & $18.8: 1$ \\
\hline Weight & $180 \mathrm{~g}$ \\
\hline
\end{tabular}


The result of the tests, which is presented in Figure 10 and Figure 11 , shows that both generators can be used for the wind turbine as both obey the Faraday's Law. As the input voltage to the testing motor increases, the output voltage from generator also increases. This is due to the increase of speed of magnetic flux cutting in the generator, driven by the increased speed of the testing motor. The output of the generator is directly proportional to the output of the generator.

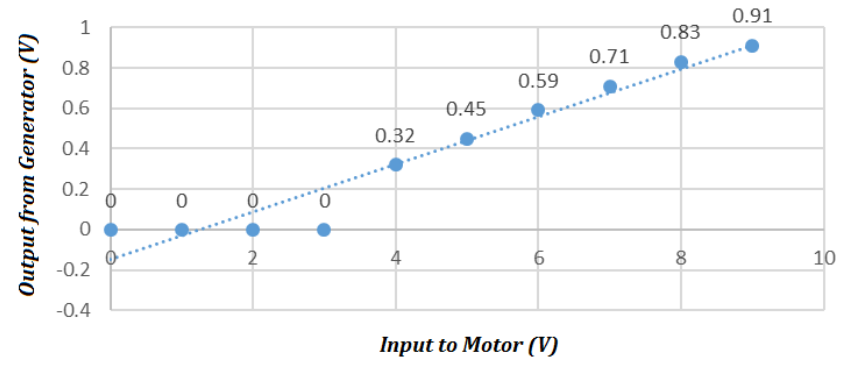

Fig. 10: JGB37-3530 testing with no load

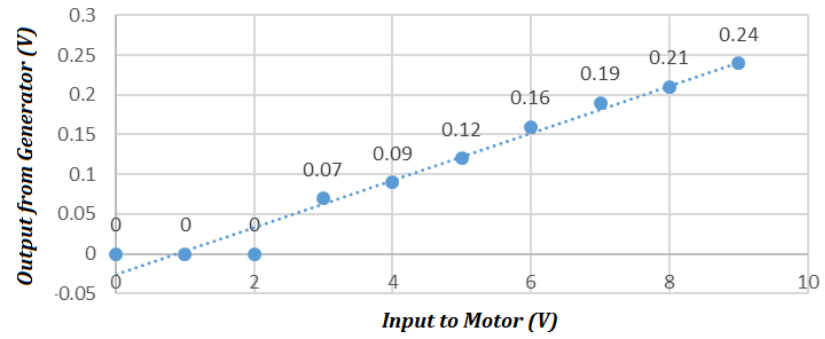

Fig. 11: M3N-2 testing with no load

Similar to first test, Figure 12 and Figure 13 show that as the input voltage to the testing motor increases, output current from generator also increases. The current output of the generator is directly proportional to the output of the generator. However, JGB37-3530 is chosen due to its higher current and voltage output compared to $\mathrm{M} 3 \mathrm{~N}-2$. At $9 \mathrm{~V}$ input to testing motor that is rotating the generator, JGB37-3530 gives out $70.1 \mathrm{~mA}$, which is almost triple than that of M3N-2, which gives out only $26.9 \mathrm{~mA}$. This result makes JGB373530 a clear choice. The reason behind higher output of JGB373530 generator is the 18.8:1 ratio gearbox attached to it. The gearbox increases the rotation of the commutator of JGB37-3530 generator, 18.8 times higher compared to that for $\mathrm{M} 3 \mathrm{~N}-2$ generator. Higher rotation of commutator means higher speed of magnetic flux cutting in the generator, hence higher current output. JGB373530 generator is used for wind turbine construction in this study.

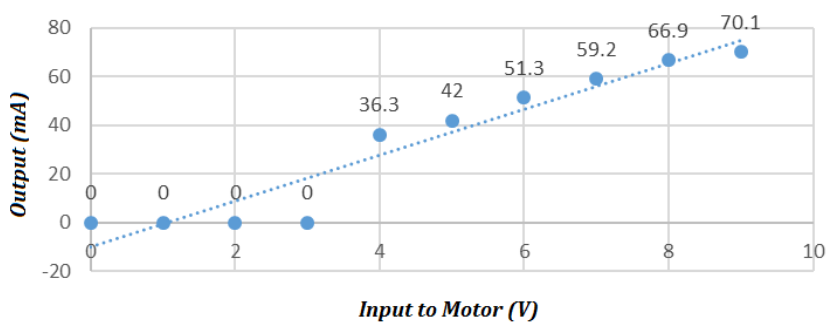

Fig. 12: JGB37-3530 testing with load

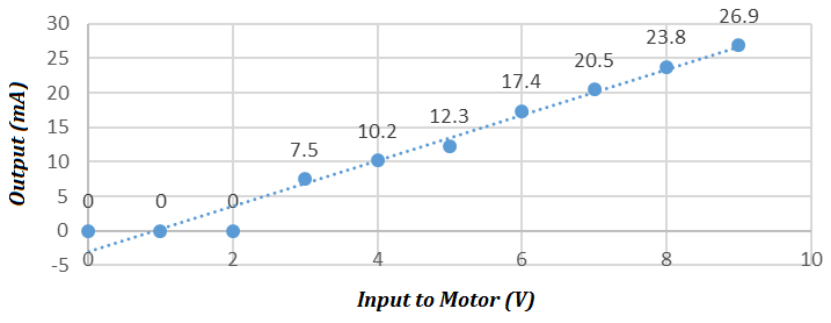

Fig. 13: M3N-2 testing with load

\subsection{Indoor testing}

The test for both wind turbines has been done in an indoor testing with steady air stream source. For this test, two variables are manipulated. The first one is the speed of air stream source and the second one is the angle of air source with respect to the direction of wind turbine. This test is done to see how both variables affect the performance of both type of wind turbine against various behaviours of the wind. The generators are tested with the load (12 $\mathrm{V}, 3 \mathrm{~W}$ bulb) and without load. The first variable that is varied during indoor testing is the speed of air stream. The output voltage and current from the wind turbines are taken.

The results of the test are presented in Figure 14 and Figure 15, which show that both wind turbines obey the Faraday's Law. As the speed of the air stream that hit the blade of the wind turbine increases, the output voltage from generator also increases. This is due to the increase of speed of magnetic flux cutting in the generator, driven by the increase speed rotation of the blade section. The voltage output of the generator is directly proportional to speed of the air stream

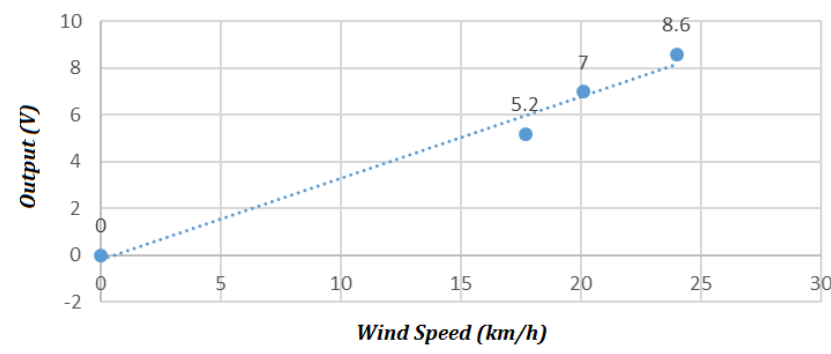

Fig. 14: HAWT indoor testing without load

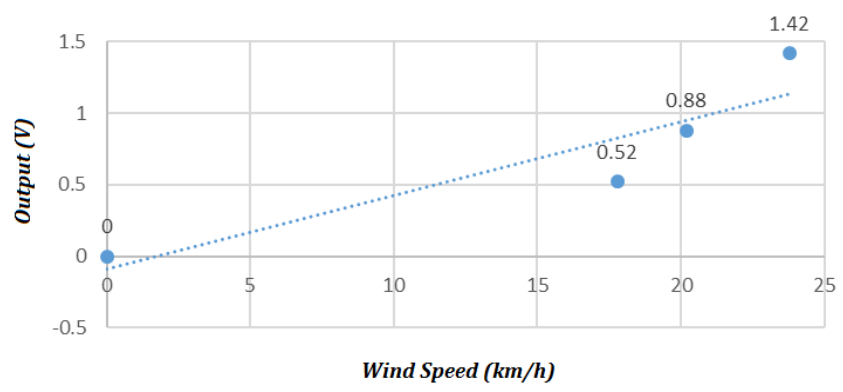

Fig. 15: VAWT indoor testing without load

Similar to the test with no load, as the speed of the air stream that hit the blade of the wind turbine increases, the output voltage from generator also increases. Current output of the generator is directly proportional to the output of the generator. However, it can be observed that there is a big difference in current and voltage output between HAWT (as shown Figure 16) and VAWT (as shown in Figure 17) in the indoor testing. At $23.8 \mathrm{~km} / \mathrm{h}$ speed of wind that is turning the blade section, HAWT produces $8.6 \mathrm{~V}$ voltage output without load and 3.85 A current output with load. Meanwhile, the VAWT produces just $1.42 \mathrm{~V}$ without load and $1.83 \mathrm{~mA}$ with load. This huge gap in current and voltage output is due to certain factors. The major factor is the weight difference between both wind turbines. The weight of the VAWT is almost double the weight of the HAWT. This factor really affects the performance of the prototype as more wind speed is needed to turn heavier blade section. Heavier prototype results in higher torque, hence reduces the wind turbine performance. Reducing weight in design is important since torque is not only affected by the weight of the blade section blade but also from the generator and friction in bearing. 


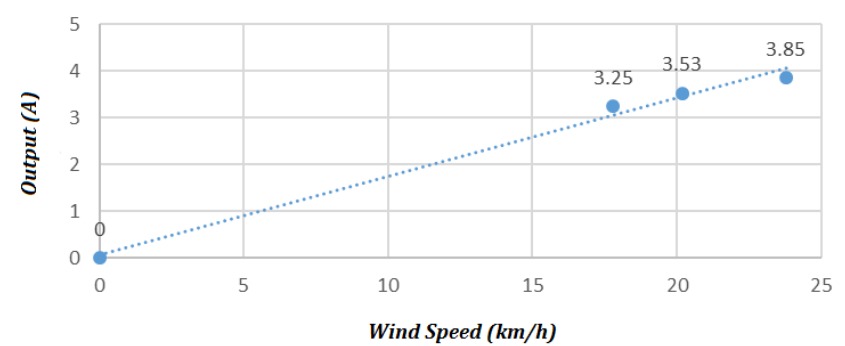

Fig. 16: HAWT indoor testing with load

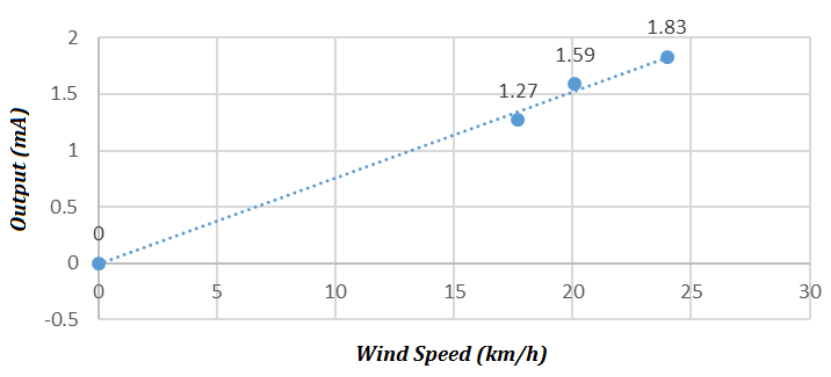

Fig. 17: VAWT indoor testing with load

The other factor that results in a huge different in current and voltage output is the efficiency between HAWT and VAWT. VAWT is not as efficient as HAWT in high-speed wind environment. This is because VAWT has exceptionally low starting torques and issues on its dynamic stability. It is also vulnerable to backtracking since its blade moves move in the same direction to the wind and it makes the blade needs to travel back into the wind flow before being push back around. Compared with HAWT, it has a greater efficiency then VAWT when extracting energy from wind force.

The second variable that has been varied during the indoor testing is the wind angle, the direction of air source with respect to direction of wind turbine and anemometer. The speed of air stream is maintained at $24 \mathrm{~km} / \mathrm{h}$. The angle is varied at $90^{\circ}, 45^{\circ}, 0^{\circ},-45^{\circ}$ and $-90^{\circ}$. The voltage output from the generator is collected. From the test, two different kinds of patterns can be seen in the graphs. Figure 18 indicates that HAWT test result starts at $0 \mathrm{~V}$ when wind angle at $90^{\circ}$, increasing to $5.10 \mathrm{~V}$ at $45^{\circ}$, reaching maximum 8.99 $\mathrm{V}$ at $0^{\circ}$, decreasing to $5.52 \mathrm{~V}$ at $-45^{\circ}$ and then reaching $0 \mathrm{~V}$ back at $-90^{\circ}$ wind angle. Compared with HAWT, VAWT has more steady output, which the voltage output maintains between $1.28 \mathrm{~V}$ to 1.4 $\mathrm{V}$ when the wind angle is changing as in Figure 19.

The difference of the pattern between both results can be explained. This is because of difference in design of the wind turbine and the two designs work efficiently in different environment. For HAWT, it is efficient in steady and also consistent air stream. This is because the design only allows it to extract energy through the full rotation of the blades when placed under a consistent wind flow directly to the direction of the blade. When the angle of the wind changes away from the direction of the blade, HAWT efficiency decreases abruptly. This is different for VAWT, which is efficient to work in unpredictable change of the wind angle. VAWT is omnidirectional and can pick up wind energy from any direction around its blade. This makes VAWT has a steady output although there are changes in angle of the wind stream.

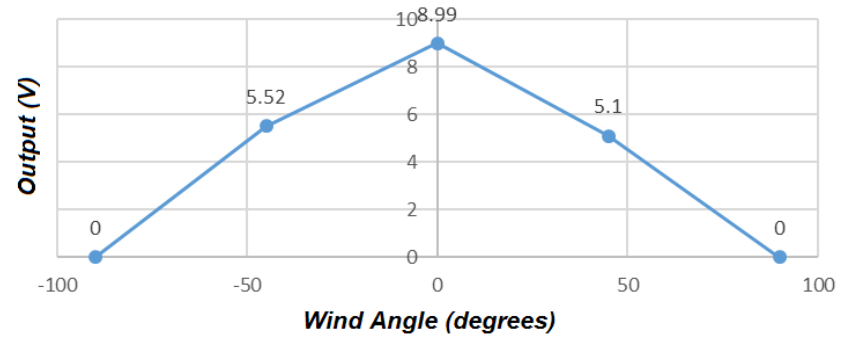

Fig. 18: HAWT angle testing

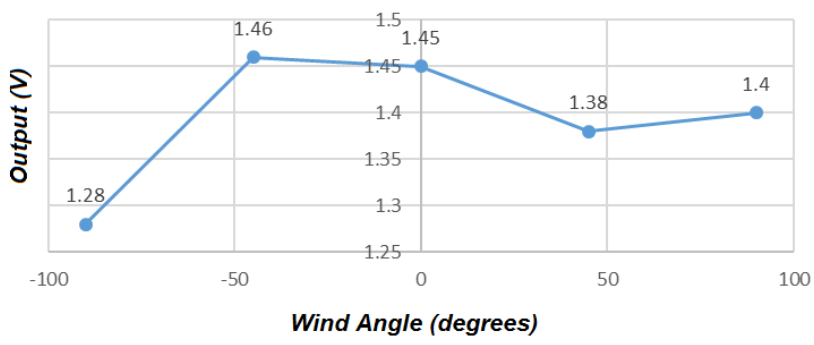

Fig. 19: VAWT angle testing

\section{Conclusion}

As energy resources in the world continuously depleting, the importance of green energy keeps rising every day. Malaysia, one of the lucky countries blessed with not just windy beaches around the country but also airports surrounded by massive, empty land areas, should optimize this gift and start considering wind energy as one of the energy sources. This can significantly boost not just Malaysian airports' performance and ranking in general [21], but also other related institutions such as aircraft maintenance training [22] and renewable energy institutions in this country. However, currently there is a lack of research in wind turbine, especially focusing between comparison of HAWT and VAWT performance in this country. This study is focused on building the functional wind turbines and comparing the performance of HAWT and VAWT under certain wind speed and behaviours, which is just one of the aspects that need to be considered. In term of power generation under steady wind stream, HAWT is clearly the better one. The HAWT is able to produce much higher energy in steady and high wind stream. However, this is not a feasible form of analysis because the two types of wind turbines are not comparable in this regard. The huge gap in current and voltage output is due the major weight difference between both wind turbines. The weight of the VAWT is almost double the weight of the HAWT. This factor really affects the performance of the prototype as more wind speed is needed to turn heavier blade section. A better comparison can be made based on the second indoor testing: wind angle change. VAWT is efficient in this environment where the direction of the wind is changing. While the performance of HAWT is dropping as the direction of the wind is away from the direction of the blade, VAWT is capable to maintain the output throughout the test. In sporadic environment, HAWT is facing the difficulties to respond while VAWT flourishes in turbulent and sporadic wind pattern. In Malaysia where the wind direction is unpredictable, a VAWT with improvable performance would most likely perform better than the HAWT due to its ability to handle turbulent and omni-directional wind.

\section{Acknowledgement}

This project is financially supported by Universiti Kuala Lumpur's Short-Term Research Grant. 


\section{References}

[1] Suruhanjaya Tenaga (2016). Malaysia Energy Statistic Handbook. Putrajaya: Suruhanjaya Tenaga

[2] Ahmad S \& Mat Tahar R (2013), Selection of renewable energy sources for sustainable development. Renewable Energy, 458-466.

[3] Ho L (2016), Wind energy in Malaysia: Past, present and future. Renewable and Sustainable Energy Reviews 53, 279-295

[4] Faizal M, Chelvan R \& Amirah A (2017), Energy, economic and environmental impact of wind power in Malaysia. International Journal of Advanced Scientific Research and Management 2(7), 8187

[5] Izadyar N, Ong HC, Chong WT, Mojumder JC \& Leong KY (2016), Investigation of potential hybrid renewable energy at various rural areas in Malaysia. Journal of Cleaner Production 139, 61-73

[6] Schreiber M (2016), Man-made "wind trees" will finally make it possible to power homes using turbines. https://qz.com/763715/ wind-trees-mini-turbines-that-can-power-homes/

[7] Wind Energy Foundation (2016), History of Wind Energy. http:// windenergyfoundation.org/about-wind-energy/history/

[8] Ab. Wahab A, Abas M \& Ismail M (2006), The influence of roughness and obstacle on wind power map. International Symposium on Renewable Energy: Environment Protection and Energy Solution

[9] Wislow AR (2017), Urban Wind Generation: Comparing Horizontal and Vertical Axis Wind Turbines at Clark University in Worcester, Massachusetts. http://commons.clarku.edu/idce_masters - papers/127

[10] Shires A \& Kourkoulis V (2013), Application of circulation controlled blades for vertical axis. Energies 2013(6), 3744-3763

[11] Saad MM \& Asmuin N (2014), Comparison of horizontal axis wind turbine and vertical axis wind turbine. IOSR Journal of Engineering 4(8), 27-30

[12] Toja-Silva F, Colmenar-Santos A \& Castro-Gil M (2013), Urban wind energy exploitation systems: Behaviour under multidirectional flow conditions - opportunities and challenges. Renewable and Sustainable Energy Reviews 24, 364-378

[13] Ab. Wahab A, Abas M \& Ismail M (2004), Establishing the Wind Map of Sabah and Sarawak. http://eprints.utm.my/id/eprint/2688/ 1/74168.pdf

[14] Moriarty MA (2008), Feasibility of Small-Scale Urban Wind Energy Generation. Thesis, University of Pittsburgh

[15] Pagnini L, Burlando M \& Repetto M (2015), Experimental powe curve of small-size wind turbines in turbulent urban environment. Applied Energy 154, 112-121

[16] Tjiu W, Marnoto T, Mat S, Ruslan M \& Sopian K (2015), Darrieus vertical axis wind turbine for power generation II: Challenges in HAWT and the opportunity of multi-megawatt Darrieus VAWT development. Renewable Energy 75, 560-571

[17] Lim LT, Auras R \& Rubino M (2008), Processing technologies for poly (lactic acid). Progress in Polymer Science 33(8), 820-852

[18] Ryan V (2017), Designing and Engineering a Sustainable Polymer Material by Blending Poly(lactic acid) and Acrylonitrile Butadiene Styrene. Thesis, University of Guelph

[19] Rutkowski JV \& Levin BC (1986), Acrylonitrile-butadiene-styrene copolymers (ABS): Pyrolysis and combustion products and their toxicity. Fire and Materials, 93 - 105

[20] Kumpulan Utusan (2016), Cuping, Alor Setar catat suhu tertinggi 38.5 darjah Celsius. http://www.utusan.com.my

[21] Bardai A, Er A, Johari MK \& Mohd Noor A (2017), A review of Kuala Lumpur International Airport (KLIA) as a competitive South-East Asia hub. IOP Conference Series: Materials Science and Engineering 270, 012039

[22] Khairuddin M, Yahya M \& Johari MK (2017), Critical needs for piston engine overhaul centre in Malaysia. IOP Conference Series: Materials Science and Engineering 270, 012013 